\title{
Modelling and Simulation of the Multi-effect/Thermal Vapor Compression Distillation Process
}

\author{
Khalid Bamardouf ${ }^{*}$, Osman Ahmed Hamed, Amro Mohammed Mahmoud \\ Thermal Department, Desalination Technologies Research Institute (DTRI-SWCC), Jubail, Saudi Arabia
}

Email address:

KBamardouf@swcc.gov.sa (K. Bamardouf)

${ }^{*}$ Corresponding author

\section{To cite this article:}

Khalid Bamardouf, Osman Ahmed Hamed, Amro Mohammed Mahmoud. Modelling and Simulation of the Multi-effect/Thermal Vapor Compression Distillation Process. International Journal of Mechanical Engineering and Applications. Vol. 8, No. 4, 2020 , pp. $103-110$. doi: 10.11648/j.ijmea.20200804.12

Received: September 14, 2020; Accepted: September 29, 2020; Published: October 12, 2020

\begin{abstract}
The Multi-effect distillation (MED) associated with thermal vapor compression (TVC) process has recently been applied for a number of desalination plants in the GCC countries and emerged as a strong competitor to the multistage flash distillation (MSF) process. The MED/TVC desalination process is characterized by low power consumption compared to the MSF process. It is currently operated at low TBT of $65^{\circ} \mathrm{C}$ to avoid scale formation compared to MSF technology which operate at top brine temperature of $110^{\circ} \mathrm{C}$, this lead to lower tendency to scale formation and less fouling risk. The use of more efficient pretreatment to MED/TVC desalination plants such as nano-filtration or high performance additive antiscalant would allow operating MED at higher TBT which allow increasing the performance ratio. A simulation steady-state program has been established to analyze the thermodynamic behavior of parallel feed flow MED/TVC unit at a wide range of TBT from $65^{\circ} \mathrm{C}$ up to $125^{\circ} \mathrm{C}$ and different number of effects with different condition of motive steam pressure on the performance ratio, and specific heat transfer and therefore the best design of MED for the future different design options were considered to optimize the operational of MED system to enhance the economics and performance of MED technology.
\end{abstract}

Keywords: MED-TVC, Desalination, Simulation, Heat and Mass Balance

\section{Introduction}

The prevailing desalination technologies nowadays are mainly: Multi Stage Flash (MSF), Reverse osmosis (RO) and Multi effects Evaporation (MED). Increasing efficiency, reducing energy consumption and lowering production cost are the main goals that most of researchers and engineers are focusing on. The multi-stage flash (MSF) desalination process was introduced as an alternative in the 1960s. It is a very reliable and dominating desalination technology and it was considered the first choice when a country needs more desalinated water particularly in Gulf regions because of its capability to produce high capacity of desalted water and the high accumulated experience for operation and maintenance. However, it consumes higher thermal energy, which reaches to $65 \mathrm{kWh} / \mathrm{m}^{3}$ at gain out ratio (GOR) of 10 . It is normally connected with power plant to use low pressure steam from exhaust of turbine in order to reduce fuel consumption. The
GOR in MSF cannot be increased more than 14 due to the limitation of increasing top brine temperature more than $121^{\circ} \mathrm{C}$ and some limitation in thermodynamic. On the other hand, its capacity is very high and can produce 20 MIGD from one distiller like in Yanbu and Ras Alkhair plants. MED can achieve higher PR than MSF with identical heat transfer area and the same temperature difference between the bottom and the first stage [3] due to high heat transfer coefficient applying the thin film evaporation in which brine occurs on one side of the tube and the condensation of vapor occurs on the other side of tube. The pumping requirements are also lower compared to MSF, which equal to about $2 \mathrm{kWh} / \mathrm{m}^{3}$ that is half of that energy required for MSF [2]. Due to these advantages, MED has recently gained more market shares in the Gulf region. Table 1 shows some of MED plants that have capacity equal or above 5 MIGD. The size of MED can also be increased significantly to reach 15 MIGD like Yanbu plant. Currently 20 MIGD MED unit is now operating in Shoiaba plant in Saudi Arabia. 
Table 1. Largest capacities MED plants in the Gulf area.

\begin{tabular}{|c|c|c|c|c|c|c|}
\hline Country name & Location & plant size MIGD & No. of Units & unit size MIGD & Comm. date & PR \\
\hline Saudi Arabia & Yanbu & 15 & 1 & 15 & 2012 & 8 \\
\hline U.A.E. & Al Fujairah & 100 & 12 & 8.3 & 2010 & 10.3 \\
\hline U.A.E. & Sharjah (Layyah) & - & - & 8.0 & - & 8.4 \\
\hline Saudi Arabia & Al Jubail (Marafiq) & 176 & 27 & 6.5 & 2010 & 9.8 \\
\hline Qatar & Ras Laffan & 63 & 10 & 6.3 & 2011 & 10.9 \\
\hline Bahrain & Al-Hidd & 60 & 10 & 6 & 2007 & 9.1 \\
\hline Kuwait & Azzour & - & - & 10.8 & - & 11.2 \\
\hline U.A.E. & Sharjah & 5 & 1 & 5 & 2001 & 8.4 \\
\hline U.A.E. & Ras Al Khaimah & 15 & 3 & 5 & 2005 & \\
\hline
\end{tabular}

MED can be designed by various shapes of configurations according to the direction of feed and vapor flow and the arrangement of heat transfer tubes. The feed flow can either be backward, forward or parallel and the arrangement of heat transfer tubes can be either designed as horizontal (HTE) or vertical tube (VTE). In the backward feed MED, vapor and brine moves through the evaporators in opposite direction, whereas in the forward feed flow, vapor and brine move through the evaporator as parallel flows from the first high temperature effect to the last low temperature effect. The feed water flow is preheated in each effect from the last effect until it reaches to the first effect. It enters the first effect where some of it evaporates when it flow down on the heat transfer tubes in which steam flow and the remaining brine is sent to the second effect by pump. In order to avoid using pump in each effect, the effects are built as vertically stacked. In the parallel feed arrangement, the feed water flow is divided into equal amount to each effect. If necessary, the feed water is heated in preheater before entering the effect. The main difference between HTE and VTE configuration is that in HTE, the heat transfer tubes inside each effect are arranged horizontally and evaporation of feed water occurs outside the tubes as a thin film, whereas in VTE, the heat transfer tubes are arranged vertically and evaporation takes inside the tubes. Most of the current MED plants are designed as parallel feed water distributed with horizontal tubes. They operate at low top brine temperature of less than $70^{\circ} \mathrm{C}[4]$ in order to reduce the scale and corrosion rate and minimizes the thermodynamic loss. They normally designed with performance ratio around 10 . Advantages of operating MED at higher TBT allow increasing number of effect so that the performance ratio increases and energy consumption reduces.

A number of simulation studies have been performed for the MED desalination process based on mass and energy balance [3-22]. Some of these models used simple assumptions that reduce their ability to simulate the actual plant data and calculate production cost, while others applied second low of thermodynamic which deal with the energy that able to produce work and is called "exergy" or "availability". Most of these models simulated MED with TVC that is considered as a heart of MED. Darwish and Alsairafi [1] developed a model assuming equal vapor generated by boiling in all effect, equal boiling temperature difference between effects, equal specific heat in order to compare MSF with MED. F. Al-Juwayhel et al [5] investigated the performance of single-effect evaporator desalination units using four different vapor compression heat pumps including mechanical vapor compressor, thermal vapor compression, the LiBr-water absorption system, and the zeolite-water adsorption system. They concluded that the specific heat transfer area decreases drastically at high boiling temperatures due to increase of the overall heat transfer coefficient. At higher motive steam pressures and brine temperature the amount of entrained vapor is increased which reduces the amount of vapor routed to the condenser and hence the specific heat transfer area of the condenser and the specific cooling water flow rates reduces. Al-Sahali and Ettouney [6] developed simple simulation model for MEDTVC. Ameri et al [11] studied the Effect of design parameters on multi-effect desalination system specifications and found that the optimum performance of MED depend on optimum number of effects which depends on sea water salinity, feed water temperature and effects temperature difference. Kamali and Mohebinia [12] developed a simulation program to improve the performance of an existing MED and found that increasing heat transfer area of the condenser by $32 \%$ lead to increase the production by $15 \%$ at the same top brine temperature of $70^{\circ} \mathrm{C}$. Aly and El-Figi [13] developed a steady state mathematical model to study the performance of forward type multi-effect desalination process and found that the performance ratio is significantly dependent on the number of effect but slightly on the top brine temperature. The high TBT would reduce the heat transfer area significantly but on the other hand running cost would increase due to low performance ratio and high consumption of treatment. El-Dessouky and Ettouney [24] compared the performance of several operating configurations, including the parallel flow (MEE-P), the parallel/cross flow (MEEPC), and systems combined with thermal (TVC) and mechanical (MVC) vapor compression. They concluded that thermal performance of TVC is higher at low TBT and larger number of effects. MEE-PC/TVC system has higher PR than MEE-P/TVC system. At higher TBT, the specific heat transfer area decreases drastically. Choi et al [14] developed a model for MED based on the second low of thermodynamic. They found that the major subsystems for exergy destruction were the TVC and effects which accounted more than $70 \%$ of the total amount. The increase of TVC entrainment ratio to $120 \%$ resulted in about $12 \%$ reduction of total heat transfer 
area. Alasfour [15] compared three different configurations of MED/TVC including ME-TVC, ME-TVC with regenerative feed heaters and ME-TVC coupled with conventional MEE system (ME-TVC+MEE) at different operation condition using a simulation model designed on first and second low thermodynamic. They concluded that ME-TVC+MEE configuration is suitable for large scale unit and use low motive steam flow. The most of exergy losses from the three configurations were found from ejector and evaporator. The first effect accounted $50 \%$ of the exergy loss when the MED coupled directly with a boiler. Decreasing temperature difference between the effects resulted in increasing the specific heat transfer area and decreasing specific heat consumption. Darwish and El-Dessouky [16] designed a simulation model based on first and second law. They reported that MED/TVC has less heat transfer surface area than MEE. They showed that the ejector and the evaporator are the main source of exergy losses. Increase of TBT while keeping bottom temperature same reduced the heat transfer area. Increase of number of effects at a given TBT would increase the heat transfer area and on the other hand it increases the gain out ratio. Hamed [17] investigated the thermal performance of the ME desalination system at different variables including number of effects, top brine temperature (TBT), inlet seawater. They concluded that the performance ratio increased with the increase of the number of effect. TBT and inlet seawater are slightly affected the plant performance. Hamed et al [18] compared the thermal performance of MED/TVC desalination system based on the first and second laws of thermodynamics with the conventional multi-effect boiling (MEE) and mechanical vapor compression (MVC) desalination system. The results revealed that the MED/TVC system yielded the least exergy destruction among the three systems. Increasing the number of effects and decreasing the TBT can reduce the exergy losses. Al-Najem et al [19] conducted a parametric analysis, using the first and second laws of thermodynamics for the TVC and MED-TVC. The study revealed that the steam ejector and the evaporator are the main source of availability destruction. Hassan and Darwish [25] developed a new correlations to determine the performance of thermal vapor compressor (TVC) which has close agreement to the Power's lines results. Kouhikamali and M [20] studied the effect of location of different locations of thermo-compressor suction in MED-TVC plants on GOR and found the best location that provide high GOR with low specific area was in the middle effects. Amer [23] developed steady state mathematical model to determine the optimum operating condition for designing MED-TVC. They showed that MED can operate with high GOR up to 18.5 using 12 effects at TBT of $67.5^{\circ} \mathrm{C}$.

\section{Materials and Methods}

The primary objective of this study is to establish a simulation program to perform comprehensive simulation studies to explore the effect of different process variables on the performance of the falling film horizontal tube evaporator parallel feed MED/TVC desalting process at wide range of TBT ranging from 65 to $125^{\circ} \mathrm{C}$.

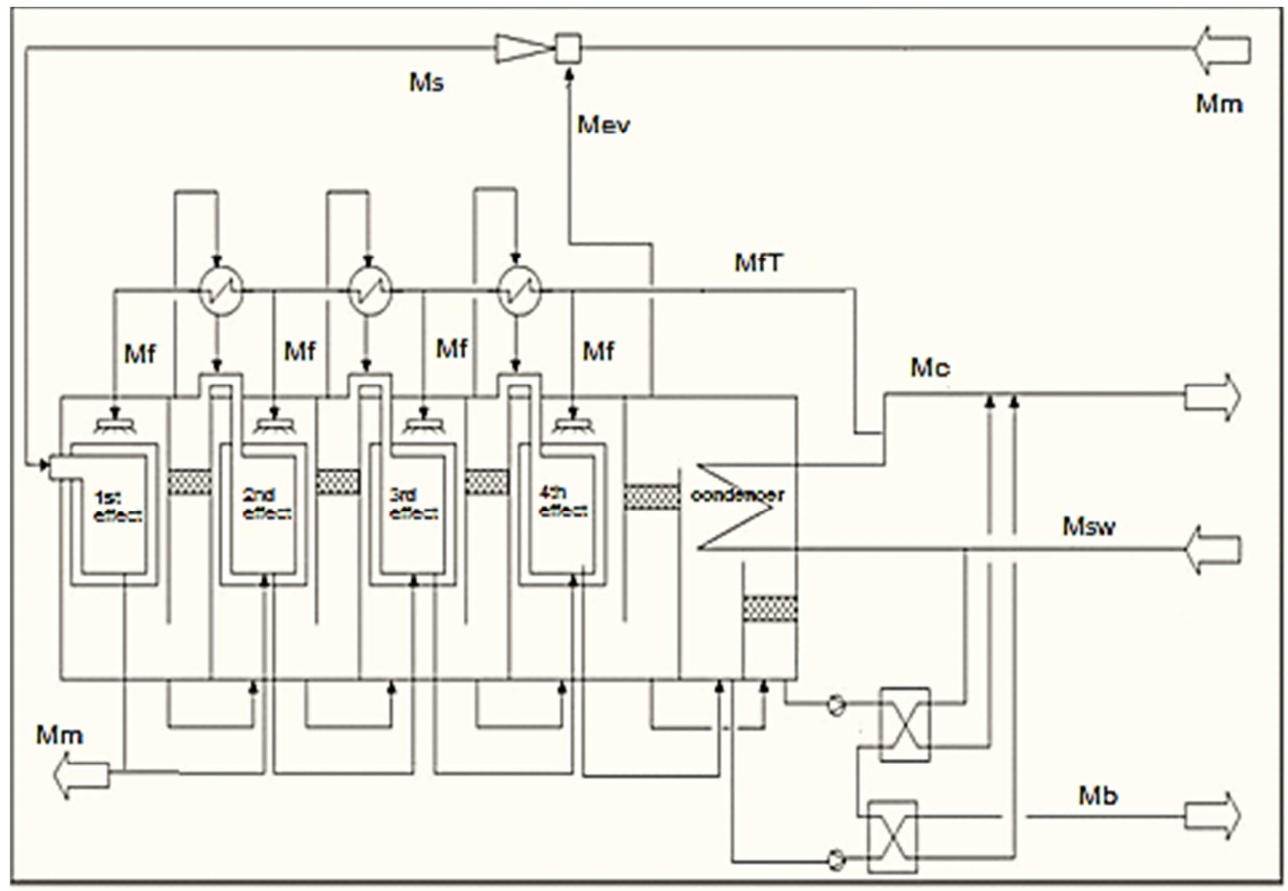

Figure 1. Schematic diagram of the parallel flow MED/TVC.

\subsection{Process Description}

Figure 1 shows a schematic diagram of the MED/TVC desalination unit. The unit consists of two major parts: vapor compression and evaporator. The evaporator consists of $n$ evaporators (effects), pre-heaters and condenser. Each effect is formed by a horizontally arranged tube bundle, a set of sea 
water nozzles, a distillate and vapor transfer ducts which includes demister section. The incoming feed sea water after passing the condenser to reject extra heat in the system is divided into two steams one goes bake to the sea while the other is divided to the $\mathrm{n}$ effects. Preheaters are installed before some effects to adjust the feed seawater temperature entering effect. Motive steam with medium or high pressure is introduced to the vapor compression to extract part of the vapor produced in the effect connected to the vapor compression. The extracted vapor mixes with the motive steam and passed to the first effect as heating steam. The steam is condensed inside the tubes while the seawater outside the tubes evaporates due to the exchange of the sensible and latent heat through the heat transfer surface between the vapor condensing inside the tubes and feed seawater film evaporating outside the tubes. Part of condensate returns to the boiler, and the other mix with the product water. The vapor produced in the first effect is directed to the second effect as a heat source to evaporate the seawater in the second effect. The process is then repeated in each effect at decreasing temperature and pressure. Finally the vapor produced in the last effect moves to the final condenser. The concentrated brine from the effects cascaded to the following effects and flash cooled in order to recover its sensible heat, finally it is passed to a cooler via the brine blow down pump. The distillate collected from the $\mathrm{n}$ effects is passed to a distillate cooler where it serves to preheat the incoming seawater.

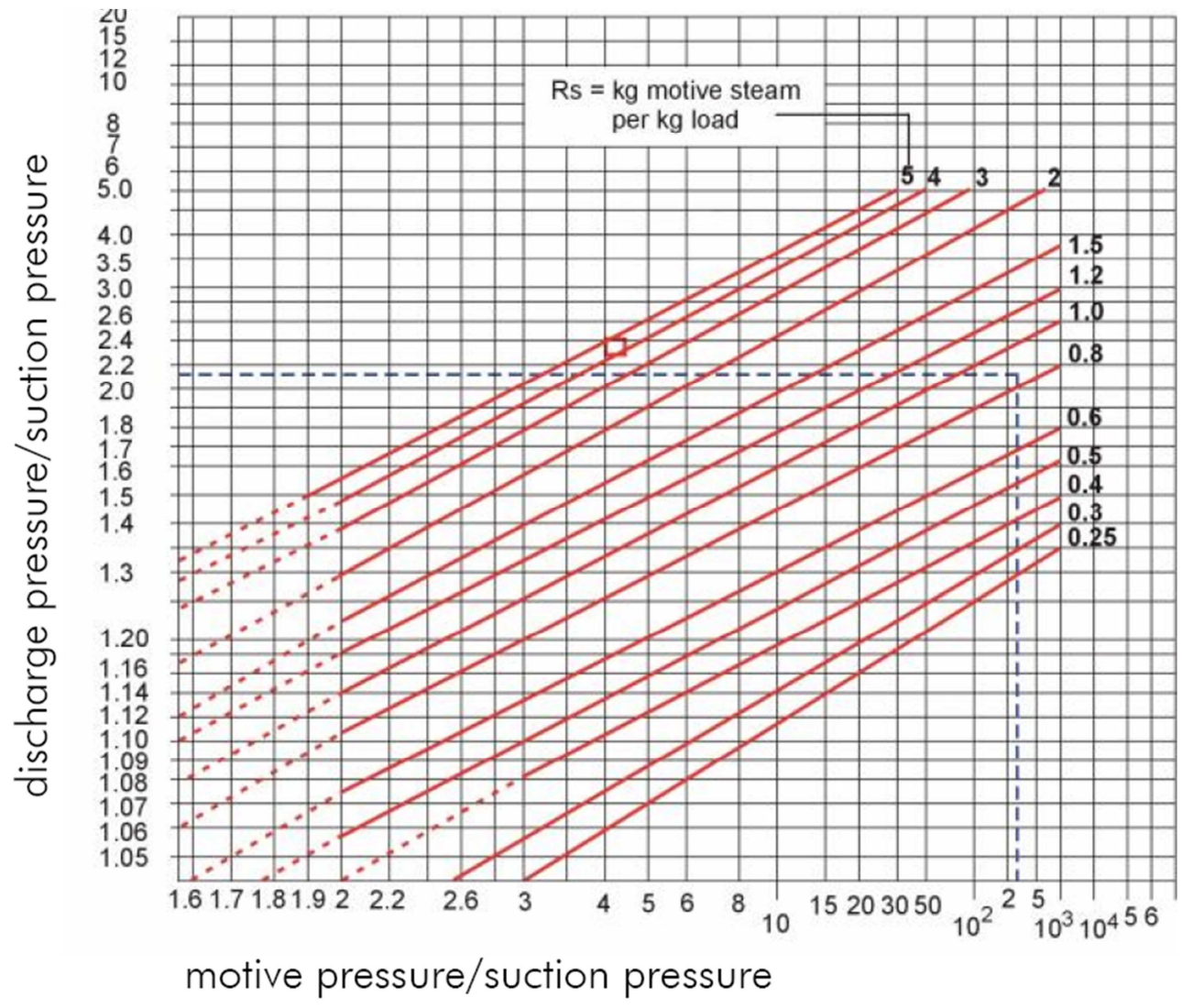

Figure 2. Function of compression ratio, CR and expansion ratio (ER).

\subsection{Model Description}

A mathematical simulation steady-state model based on first and second low of thermodynamic has been developed to predict the performance of parallel feed MED/TVC. The model was assumed working at steady state operation with negligible heat losses to the surrounding. The vapor temperature profile inside the effects was assumed to be linear with the feed temperature difference across the preheaters is assumed to be equal to the vapor temperature drop between the two successive effects.

The physical properties of the liquid streams were calculated as a function of seawater temperature and salinity. Thermodynamic losses mainly boiling point elevation was included in the model. The model was designed to allow changing the location of suction point of the thermal vapor compression and number of pre-heaters to be placed between any two effects for the optimization purpose.

The mass balance for the first effect:

$$
\begin{gathered}
\mathrm{Mb}_{1}=\mathrm{Mf}_{1}-\mathrm{Md}_{1} \\
\mathrm{Xb}_{1} \mathrm{Mb}_{1}=\mathrm{Xf}_{1} \mathrm{Mf}_{1}
\end{gathered}
$$

Where $\mathrm{Mb}$ is the brine flow, $\mathrm{Mf}$ is the feed flow and $\mathrm{Md}$ is the distillate vapor flow. $\mathrm{Xb}$ represents salt concentration

The energy balance equation for the first effect

$$
M s \lambda_{s}=M f_{1} C_{p}\left(T_{b 1}-T_{f 1}\right)+M d_{1} \lambda_{d 1}
$$

The latent heat of the formed vapor $\lambda_{d 1}$ is evaluated at the 
vapor temperature, T_vi, below the demister, which is lower than the brine temperature by the boiling point elevation

$$
T_{v i}=T_{B i}-B P E_{i}
$$

For the other effects, the mass balance

$$
M f_{i}+M b_{(i-1)}=M d_{i}+M b_{i}
$$

The Energy Balance

$$
\begin{gathered}
M v_{i+} M f_{i} H f_{i}+M b_{(i-1)} H b_{(i-1)}=M c_{i} H c_{i}+M d_{i} H d_{i}+ \\
M b_{i} H b_{i}
\end{gathered}
$$

The mass balance in the vapor compression (TVC) is given by

$$
M s=M m+M e v
$$

Where

Ms is the steam flow going to the 1 st effect, $\mathrm{Mm}$ is the motive steam and Mev is the entrained vapor

The cooling seawater flow rate can be obtained by applying energy balance on the condenser

$$
\mathrm{Mc}=\frac{\mathrm{Mv} \cdot \lambda_{\mathrm{n}}}{\mathrm{C}(\mathrm{Tcw}-\mathrm{Tsw})}
$$

Where $\mathrm{Mv}$ is the mass flow rate of vapor entering the condenser, $\lambda \_n$ is the latent heat of the vapor entering the condenser, Tcw and Tsw is the temperature of seawater and cooling water after the condenser.

Part of generated vapor from certain effect is sucked by thermal vapor compression (TVC) using motive steam at medium pressure and send it back to the first effect in order to increase the performance of MED. The ratio of the entrained vapor flow to the motive steam flow is called entrainment ratio $\mathrm{Ra}=\mathrm{Mev} / \mathrm{Mm}$. There is several correlations used to calculated entrainment ratio [26]. Power's graphical data (Figure 2) is a well-established method for obtaining entrainment ratio but it is difficult to use in simulation studies. Hassan and M. A. Darwish [25] convert the power's graphical data method to a mathematical model that easy to use in the simulation model. The model is a function of compression ratio, $\mathrm{CR}$ and expansion ratio and consists of three correlations based on the ER.

Where

$$
\begin{aligned}
& C R=\frac{P_{s}}{P_{e v}} \\
& E R=\frac{P_{m}}{P_{e v}}
\end{aligned}
$$

Ps, Pev, Pm is the discharge pressure, entrained vapor pressure and motive steam pressure respectively

The heat transfer area in the effects is calculated by

$$
A e_{i}=\frac{Q_{i}}{U e_{i} M T D e_{i}}
$$

Where

Qi is the latent heat of condensation (thermal load) of each effect
Uei is the overall heat transfer coefficient,

$$
\mathrm{MTDe}_{\mathrm{i}}=\mathrm{Tv}_{\mathrm{i}}-\mathrm{Tb}_{\mathrm{i}}-\beta-\gamma-\delta
$$

Where $\beta, \gamma, \delta$ are temperature losses due to demister, temperature losses due to tube side and temperature losses due to boiling point elevation. The overall heat transfer coefficients for tube effects are calculated using the following correlations:

The system performance of a MED-TVC can be evaluated using the following methods:

Performance Ratio (P.R.) which is defined as the amount of desalted water produced by condensing $1 \mathrm{~kg}$ of steam at an average temperature corresponding to $2326 \mathrm{~kJ} / \mathrm{kg}$ latent heat.

$$
P R=\frac{2326(M d)}{M m\left(h_{m}-h_{c}\right)}
$$

Gain output ratio (GOR), which is defined as the mass flow rate of production over the mass flow rate of steam. However, since GOR does not account for steam temperature, it can be useful in comparison only when the temperature difference heating steam temperature is the same.

The Specific heat transfer area defined as the total area of heat transfer over the total production of water.

The solution algorithm starts with definition of the following parameters: number of effects, total distillate flow rate, heating steam temperature, seawater salinity, seawater temperature, temperature of rejected cooling water and vapor

\begin{tabular}{|c|c|c|c|}
\hline \multirow{2}{*}{ Description } & \multicolumn{2}{|c|}{ Yanbu Plant } & \multirow{2}{*}{$\begin{array}{l}\text { \% } \\
\text { difference }\end{array}$} \\
\hline & Design & Model & \\
\hline No. of effect & 5 & input & - \\
\hline Production $(\mathrm{kg} / \mathrm{s})$ & 789.2 & input & - \\
\hline Motive steam pressure (bar) & 15 & input & - \\
\hline Seawater Temperature $\left({ }^{\circ} \mathrm{C}\right)$ & 33 & input & - \\
\hline Cooling seawater temperature $\left({ }^{\circ} \mathrm{C}\right)$ & 42 & input & - \\
\hline Seawater concentration (ppm) & 45000 & input & - \\
\hline Top brine temperature $\left({ }^{\circ} \mathrm{C}\right)$ & 65 & input & - \\
\hline Entrainment ratio & 1.23 & input & \\
\hline Motive steam flow to TVC $(\mathrm{kg} / \mathrm{s})$ & 97.70 & 95.24 & 2.6 \\
\hline Steam to MED (kg/s) & 218.38 & 217.6 & 0.4 \\
\hline Brine discharge flow $(\mathrm{kg} / \mathrm{s})$ & 1,973 & 1,973 & 0 \\
\hline Seawater flow to the condenser $(\mathrm{kg} / \mathrm{s})$ & 5,556 & $5,5229.5$ & 5.9 \\
\hline Feed seawater $(\mathrm{kg} / \mathrm{s})$ & 2,763 & 2,762 & 0 \\
\hline GOR & 8.1 & 8.3 & 2.2 \\
\hline
\end{tabular}
temperature in the last effect. The equations used in the model are interlinked and highly nonlinear so that iterative solution was required to obtain the results.

\subsection{Validation the Model}

The model was validated with the design data of Yanbu plant MED/TVC plant that has capacity of 15 MIGD. The mass and energy balance results showed good agreement between the design data and the model as shown in the Table 2.

Table 2. MED Yanbu plant specification. 


\section{Results and Discussion}

The simulation model was run with different TBT ranging between 65 to $125^{\circ} \mathrm{C}$ in order to study its effect on the performance of parallel feed MED/TVC. Temperature of seawater, cooling water and the last effect temperature were fixed during all trial calculations at $35^{\circ} \mathrm{C}, 41.6^{\circ} \mathrm{C}$ and $43.6^{\circ} \mathrm{C}$, respectively. Temperature difference between feed water and vapor inside, the tube was adjusted to be not more than $7^{\circ} \mathrm{C}$ as the practice used in the design. Preheater is added when the temperature difference exceeds this limit. The TDS of seawater and brine in the last effect were assumed to be at 45000 and 64400 ppm respectively. The number of effects in MED was restricted by the assumption that the temperature difference between the two successive effect should be not less than $2.5^{\circ} \mathrm{C}$ and not more than $8{ }^{\circ} \mathrm{C}$ which based on the practical design application to keep the specific heat transfer area in the acceptable range in the range of $350 \mathrm{~m}^{2} / \mathrm{kg} / \mathrm{s}$ as per data collected from of multi stage flash (MSF) plants operated in SWCC (table 3). The impact of the number of effects and motive steam pressure on the performance ratio and specific heat transfer at different top brine temperature will be discussed in this section.

Table 3. Specific heat transfer area for some of MSF plants.

\begin{tabular}{llll}
\hline MSF Plant & TBT $^{\circ} \mathbf{C}$ & GOR & $\mathbf{A}_{\mathbf{d}} \mathbf{~ m}^{2} / \mathbf{k g} / \mathbf{s}$ \\
\hline Jubail I & 90.6 & 7.87 & 293.6 \\
Jubail II & 112.8 & 9 & 267.3 \\
Jeddah III & 108 & 7.1 & 205.7 \\
Jeddah IV & 110 & 7 & 167.2 \\
Yanbu I & 121 & 10 & 217.6 \\
Khobar II & 110 & 6.5 & 193.4 \\
Shugayg & 90 & 9.5 & 351.6 \\
\hline
\end{tabular}

The output for different cases is summarized in this part, Figure 3 shows the impact of increasing the number of effects at different top brine temperature. Increasing the number of effects at a specific TBT leads to increase the performance ratio and on the other hand the specific heat transfer area will also increase. Most of the MED units working today are designed to operate at TBT of $65^{\circ} \mathrm{C}$ to avoid scale formation. Based on the simulation results the performance ratio and the specific heat transfer area of MED unit with 5 effects and operates at TBT of $65^{\circ} \mathrm{C}$ is 7.4 and $186 \mathrm{~m}^{2} / \mathrm{kg} / \mathrm{s}$ respectively. The performance ratio can be increased to 13.7 by increasing number of effects to 9 effect but the specific heat transfer area will increase to $395 \mathrm{~m}^{2} / \mathrm{kg} / \mathrm{s}$

The higher TBT the greater number of effects can be added and thus the higher the performance ratio. Using Nanofiltration, it can be designed MED unit with TBT of $125^{\circ} \mathrm{C}$. The performance ratio can reach to 25 when the MED unit is designed with 27 effects with specific heat transfer area of $351 \mathrm{~m}^{2} / \mathrm{kg} / \mathrm{s}$, as shown in Figure 4 .

The possibility of operating the units at TBT of $85^{\circ} \mathrm{C}$ was tested in DTRI pilot plant located in Jubail [28] so that the number of effects can be increased to 14 or 15 effects which lead to increase the performance ratio to 16.2 or 18 within the acceptable range of specific heat transfer area $\left(350 \mathrm{~m}^{2} / \mathrm{kg} / \mathrm{s}\right)$.
This means that thermal energy consumption will reduce by more than $100 \%$ as compared to the existing MED units with performance ratio of 8 . It should be noted that when the TBT is increased from $65^{\circ} \mathrm{C}$ to $85^{\circ} \mathrm{C}$ keeping the specific heat transfer area same, the performance ratio will increase to 10.8 which means $46 \%$ reduction in fuel consumption. By this way, increasing TBT brings about in lowering the operational cost without additional heat transfer area that represents the main part of the capital cost.

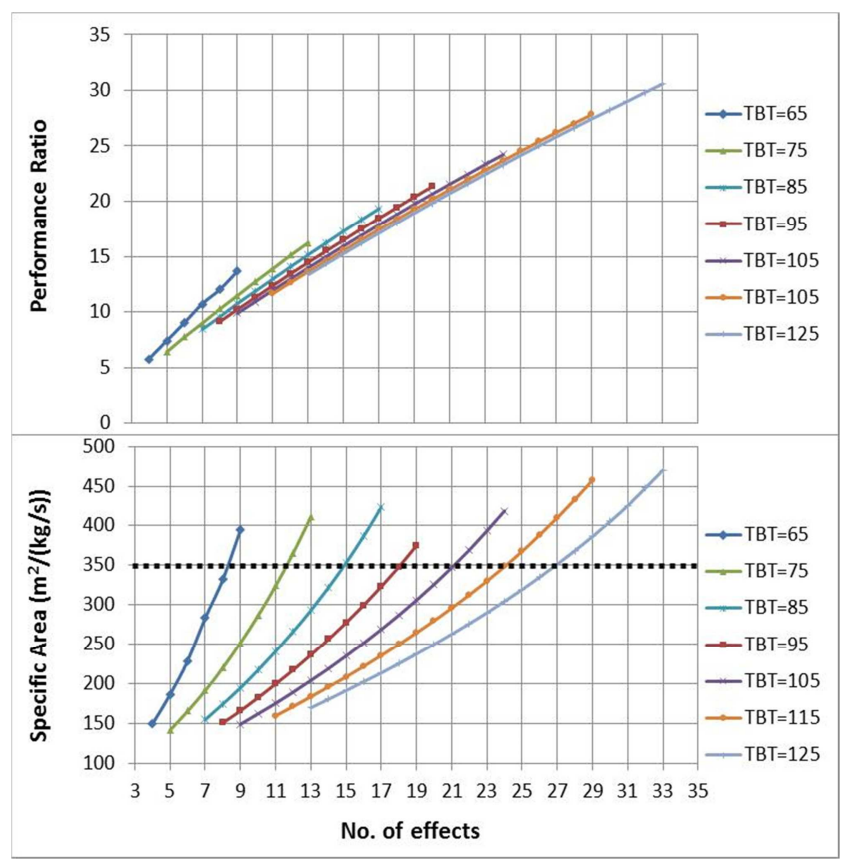

Figure 3. Performance and specific heat transfer area versus number of effects at different TBT.

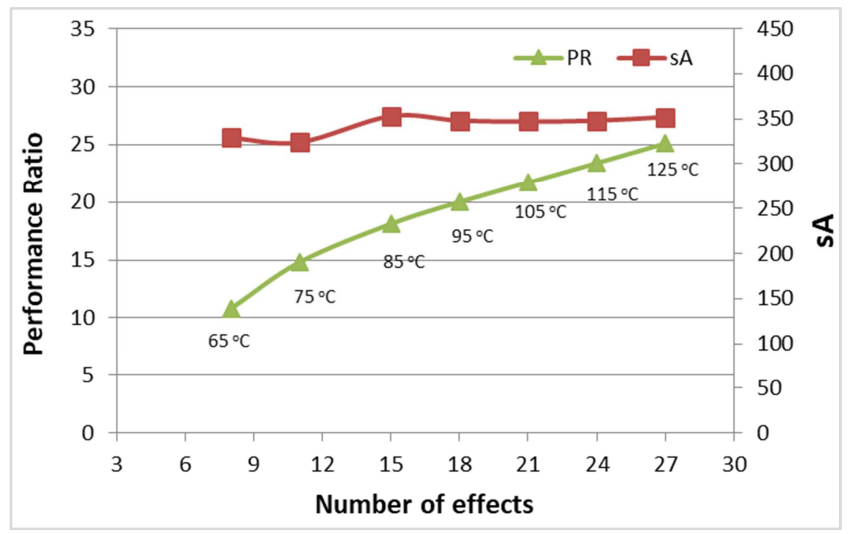

Figure 4. The optimum performance ratio with specific heat transfer area around $350 \mathrm{~m}^{2} / \mathrm{kg} / \mathrm{s}$.

Entrained vapor is a critical criteria to determine the performance ratio in MED TVC. Motive steam pressure is one factor that affects the entrainment ratio. Figure 5 shows the relationship between the motive steam pressure and the entrainment ratio at different compression ratio, (Ps/Pev), based on the correlation developed by (Hassan and Darwish) [25]. It shows the entrainment ratio increases when the motive steam pressure increases until certain point (around 
20 bar) after that more pressure would have limited effect on the entrainment ratio. This result matches with the results obtained by El-Allawy et al.[27].

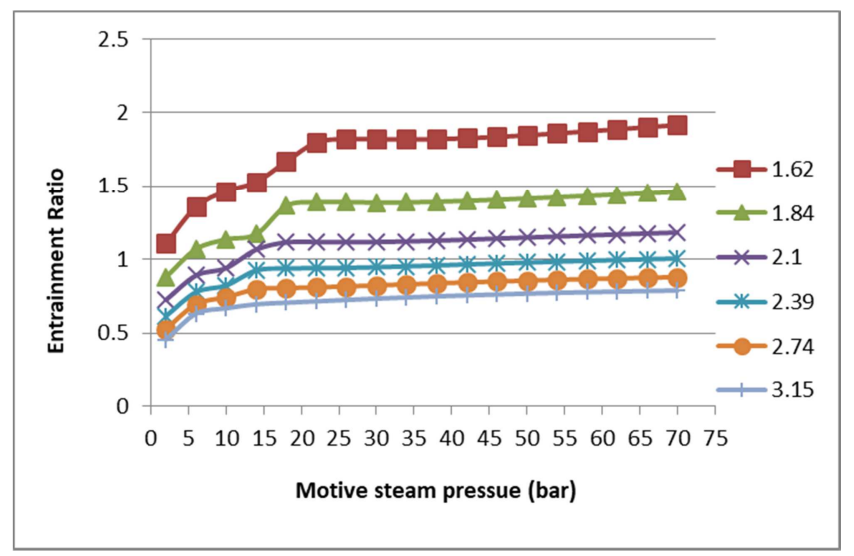

Figure 5. Compression ratio vs. entrainment ratio.

\section{Conclusions}

The impact of the different process and operating variables on the thermal effectiveness of the parallel MED/TVC were explored. The effect of the number of effects, top brine temperature, motive steam pressure on the performance ratio, and specific heat transfer area were studied in order to identify the most thermodynamically efficient condition for operation. The conclusions can be summarized as follow:

1. The opportunity to increase the performance of MED is very high and extensive.

2. Increasing number of effect is limited by the temperature drop between the effects.

3. Increasing TBT allows more number of effects to be added without change in the temperature drop so that the specific heat transfer area will be maintained in the acceptable range $\left(250-350 \mathrm{~m}^{2} / \mathrm{kg}\right.$.s $)$.

4. Operating MED at a TBT of $125^{\circ} \mathrm{C}$ using nanofiltration will allow to increase the number of effects up to 27 effects which leads to performance ratio of 25.8.

5. Operating MED at TBT of $85^{\circ} \mathrm{C}$ using antiscalant is very promising which leads to increase the performance ratio to 17.3 with 15 effects. This will result in reduction of fuel consumption by $26.5 \%$ compared to MED unit working with TBT of $65^{\circ} \mathrm{C}$ and 9 effects and having performance ratio of 13.7 .

6. The entrainment ratio which is defined as the ratio of entrained vapor flow over the motive steam flow, can be increased by raising the motive steam pressure. The motive steam pressure has high effect at low pressure and limited effect at pressure more than 20 bar.

7. The performance ratio also slightly changes by the location of sucking point of TVC so that optimization for the best location of TVC is required.

\section{Nomenclatures}

$\begin{array}{ll}\text { Cr: } & \text { Compression ratio (discharge pressure/entrained vapor pressure) } \\ \mathrm{Er}: & \text { Expansion ratio (motive steam pressure/entrained vapor pressure) } \\ \mathrm{Md}: & \text { Mass flow rate of distillate vapor from each effect, } \mathrm{kg} / \mathrm{s} \\ \mathrm{Mev}: & \text { Mass flow rate of entrained vapor, } \mathrm{kg} / \mathrm{s} \\ \mathrm{Mm}: & \text { Mass flow rate of motive steam, } \mathrm{kg} / \mathrm{s} \\ \mathrm{Ra}: & \text { Entrainment ratio (motive steam flow rate / entrained vapor flow rate) } \\ \mathrm{Ps}: & \text { Pressure of discharge mixed steam, } \mathrm{kPa} \\ \mathrm{Pm}: & \text { Pressure of motive steam, } \mathrm{kPa} \\ \text { Pev: } & \text { Pressure of entrained vapor, } \mathrm{kPa}\end{array}$

\section{References}

[1] Darwish, M. A. and A. Alsairafi, Technical comparison between TVC/MEB and MSF. Desalination, 2004. 170 (3): p. 223-239.

[2] Emmermann, D., An advanced barge mounted VTE/VC for the desalination of seawater. Desalination, 1981. 38: p. 13-20.

[3] agency, I. a. e., Desalination Economic Evaluation Program. 2000.

[4] El-Nashar, A. M., Predicting part load performance of small MED evaporators - a simple simulation program and its experimental verification. Desalination, 2000. 130 (3): p. 217234.

[5] Al-Juwayhel, F., H. El-Dessouky, and H. Ettouney, Analysis of single-effect evaporator desalination systems combined

with vapor compression heat pumps. Desalination, 1997. 114 (3): p. 253-275.

[6] Al-Sahali, M. and H. Ettouney, Developments in thermal desalination processes: Design, energy, and costing aspects. Desalination, 2007. 214 (1-3): p. 227-240.

[7] Zhe Dong, et al., Dynamical modeling and simulation analysis of a nuclear desalination plantbased on the MED-TVC process. Desalination,2019. 456: p.121-135.

[8] Nafey, A. S., et al., Exergy And Thermo-Economics Investigation Of Multi Effect Evaporation (Mee) And Hybrid Multi Effect Evaporation - Multi Stage Flash (Mee-Msf) Systems, in Ninth International Water Technology Conference. 2005: Sharm El-Sheikh, Egypt.

[9] El-Dessouky, H. T., H. M. Ettouney, and F. Al-Juwayhel, Multiple Effect Evaporation-Vapour Compression Desalination Processes. Chemical Engineering Research and Design, 2000. 78 (4): p. 662-676. 
[10] Y. Guo, et al., Effects of preheater arrangement on performance of MED desalination system. Desalination,2020. 496: 114702.

[11] Ameri, M., et al., Effect of design parameters on multi-effect desalinationsystem specifications. Desalination, 2009. 245 (13): p. 266-283.

[12] Kamali, R. K. and S. Mohebinia, Experience of design and optimization of multi-effects desalination systems in Iran. Desalination, 2008. 222 (1-3): p. 639-645.

[13] Aly, N. H. and A. K. El-Figi, Thermal performance of seawater desalination systems. Desalination, 2003. 158 (1-3): p. $127-142$.

[14] Choi, H.-S., et al., Performance improvement of multipleeffect distiller with thermal vapor compression system by exergy analysis. Desalination, 2005. 182 (1-3): p. 239-249.

[15] Alasfour, F. N., M. A. Darwish, and A. O. Bin Amer, Thermal analysis of $M E-T V C+M E E$ desalination systems. Desalination, 2005. 174 (1): p. 39-61.

[16] Darwish, M. A. and H. El-Dessouky, The heat recovery thermal vapour-compression desalting system: A comparison with other thermal desalination processes. Applied Thermal Engineering, 1996. 16 (6): p. 523-537.

[17] Hamed, O. A., Thermal assessment of a multiple effect boiling (MEB) desalination system. Desalination, 1992. 86 (3): p. 325-339.

[18] Hamed, O. A., et al., Thermal performance and exergy analysis of a thermal vapor compression desalination system. Energy Conversion and Management, 1996. 37 (4): p. 379387.

[19] Al-Najem, N. M., M. A. Darwish, and F. A. Youssef, Thermovapor compression desalters: energy and availability -
Analysis of single- and multi-effect systems. Desalination, 1997. 110 (3): p. 223-238.

[20] Kouhikamali, R. and M. M. S. M, Process investigation of different locations of thermo-compressor suction in MEDâ€ TVC plants. Desalination. 280 (13): p. 134-138.

[21] K. A. Khalid, M. A. Antar, A. Khalifa, O. A. Hamed, Allocation of thermal vapour compressor in multi effect desalination systems with different feed configurations, Desalination 426 (2018) 164-173.

[22] Ettouney, H., Visual basic computer package for thermal and membrane desalination processes. Desalination, 2004. 165: p. 393-408.

[23] Amer, A., Development and optimization of ME-TVC desalination system. Desalination, 2009. 249 (3): p. 13151331 .

[24] El-Dessouky, H. T. and H. M. Ettouney, Multiple-effect evaporation desalination systems. thermal analysis. Desalination, 1999. 125 (1-3): p. 259-276.

[25] Hassan, A. S. and M. A. Darwish, Performance of thermal vapor compression. Desalination. 335 (1): p. 41-46.

[26] El-Dessouky H. T. and H. M. Ettouney, Fundamentals of Salt Water Desalination. 2002: ELSEVIER.

[27] El-Allawy, M. Predictive simulation of the performance of $\mathrm{med} / \mathrm{tvc}$ desalination distiller. in IDA World Congress, International Desalination Association, Bahamas. 2003.

[28] Younggeun Lee, Osman Ahmed Hamed, Amr Mohammad Mahmoud, Khalid Bamardouf, Sultan Ahmed, Byungsung Park, Abdulaziz Suliman Al-Jamhan, A Demonstration of High Temperature MED-TVC Desalination Technology in the Gulf Area, American Journal of Chemical Engineering. Vol. 7, No. 2, 2019, pp. 57-64. doi: 10.11648/j.ajche.20190702.11 